\title{
Erratum to: The variability of peridotite composition across a mantle shear zone (Lanzo massif, Italy): interplay of melt focusing and deformation
}

\author{
M.-A. Kaczmarek • O. Müntener
}

Published online: 11 July 2010

(C) Springer-Verlag 2010

Erratum to: Contrib Mineral Petrol

DOI 10.1007/s00410-010-0500-8

Unfortunately, there are some errors in Fig. 9 and its caption in the original publication of the article. The correct figure and the caption are given on the following page.

The online version of the original article can be found under doi:10.1007/s00410-010-0500-8.

M.-A. Kaczmarek

Institute of Geology, University of Neuchâtel, rue Emile Argand,

2007 Neuchâtel, Switzerland

Present Address:

M.-A. Kaczmarek ( $\square)$

Géosciences Montpellier UMR 5243, CC60 Université

Montpellier 2 Place E. Bataillon,

34095 Montpellier Cedex 5, France

e-mail: mary-alix.kaczmarek@gm.univ-montp2.fr

O. Müntener

Institute of Mineralogy and Geochemistry,

University of Lausanne, Anthropôle,

1015 Lausanne, Switzerland 
Fig. 9 Trace element variations diagrams of $\mathbf{a ~ N b}$ and $\mathbf{b}$ Th vs. Ce (ppm). The Lanzo peridotite massif is compared to published data from the Lherz (Bodinier et al. 2008) and Malenco massifs (Müntener 1997), from the Mid-Atlantic Ridge (Godard et al. 2008; Paulick et al. 2006) and the Oman ophiolite (Godard et al. 2000) and peridotite from a supra-subduction zone (IzuBonin-Mariana) (Parkinson and Pearce 1998). Note that all analyses were performed at the Montpellier 2 University except (Parkinson and Pearce 1998).

PM (McDonough and Sun 1995) DMM and N-MORB (Sun and McDonough 1989) are shown for references
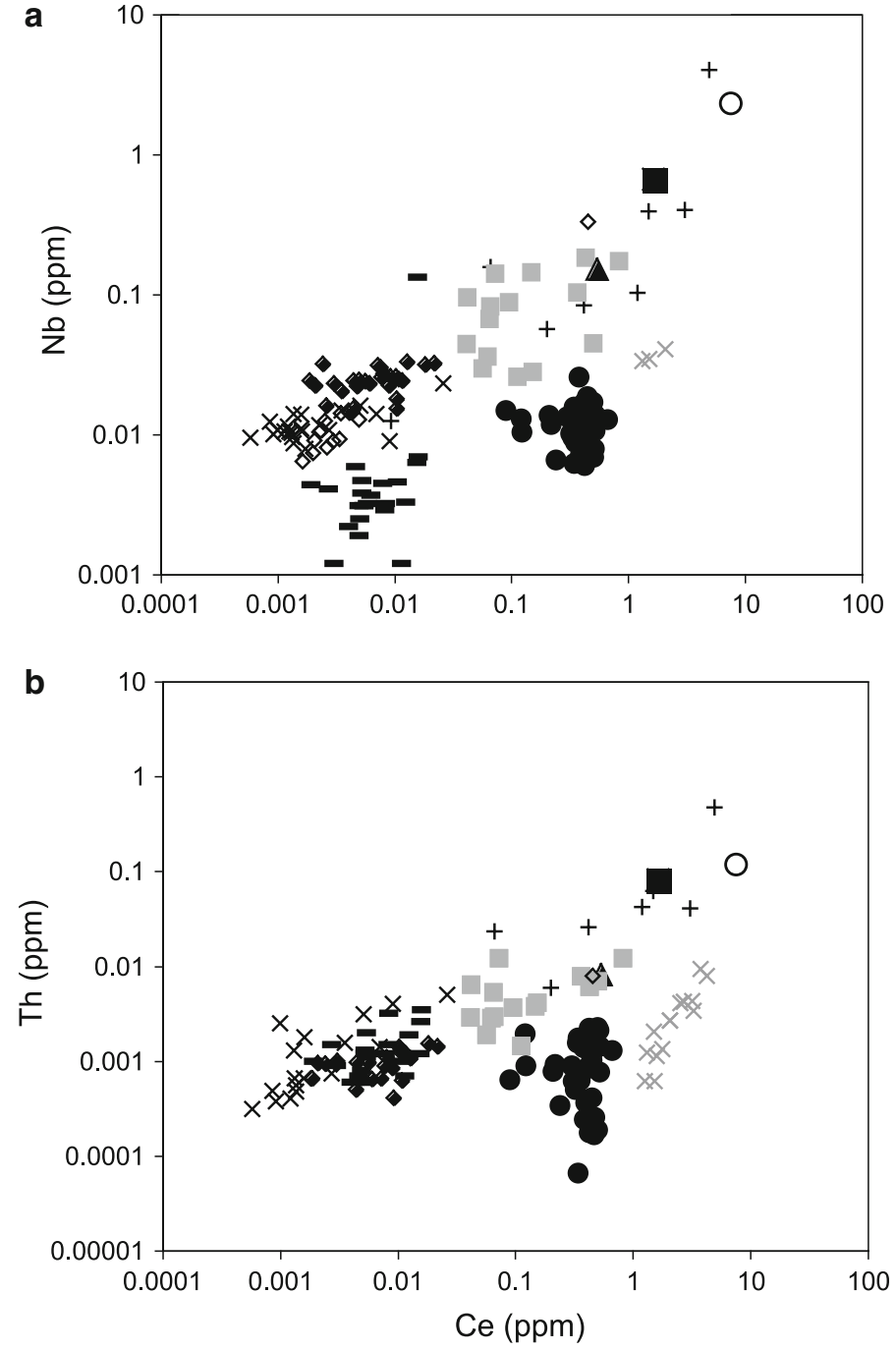

this study

Müntener 1997

- Godard et al. 2000

Paulick et al. 2006

$\times$ Bodinier et al. 2008

$\times$ Godard et al. 2008

PM

+ 1070-1071 sites

- Parkinson and Pearce 1998
O N-MORB

$\triangle \mathrm{DMM}$ 